\title{
Commentary: Doing what is right-We are all in this together
}

Check for updates

\author{
Frederick L. Grover, MD, ${ }^{\mathrm{a}}$ and Joseph C. Cleveland, Jr, MD ${ }^{\mathrm{a}, \mathrm{b}}$
}

\footnotetext{
From the ${ }^{\mathrm{a}}$ Division of Cardiothoracic Surgery, Department of Surgery, University of Colorado School of Medicine-Anschutz Medical Campus, Aurora, Colo; and the ${ }^{\mathrm{b}}$ Cardiac Transplantation Program, Division of Cardiothoracic Surgery, Department of Surgery, University of Colorado School of Medicine-Anschutz Medical Campus, Aurora, Colo.

Disclosures: Dr Grover is past chair of the Society of Thoracic Surgeons Workforce on National Databases and a consultant for JenaValve Technologies, Inc. Dr Cleveland declares a financial interest in Abbott Medical.

Received for publication Jan 23, 2019; accepted for publication Jan 23, 2019; available ahead of print March 8, 2019.

Address for reprints: Frederick L. Grover, MD, Department of Surgery, University of Colorado Denver School of Medicine, Mail Stop C310, Academic Office 1, 12631 E 17th Ave. Aurora, CO 80045 (E-mail: Frederick. Grover@ucdenver.edu).

J Thorac Cardiovasc Surg 2020;159:554-5

$0022-5223 / \$ 36.00$

Copyright $(c) 2019$ by The American Association for Thoracic Surgery

https://doi.org/10.1016/j.jtcvs.2019.01.090
}

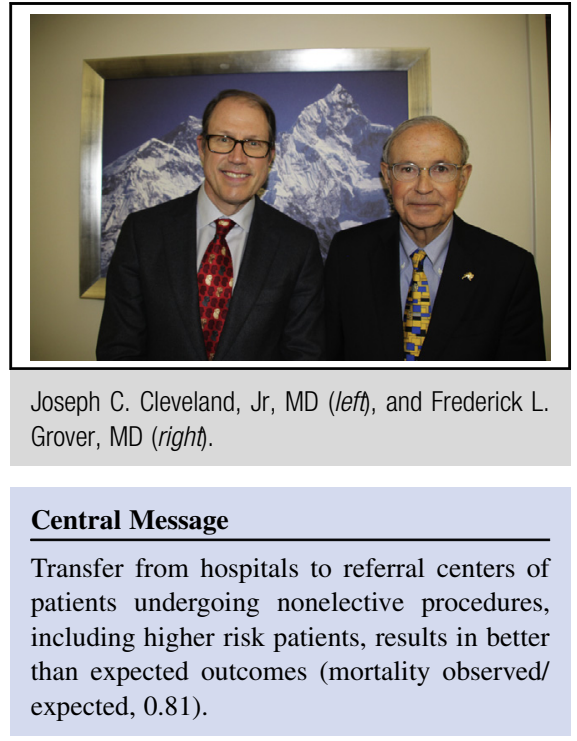

See Article page 540
In this issue of the Journal, Beller and colleagues ${ }^{1}$ have addressed the issue of the effect of transfer status on real-world outcomes in nonelective cardiac surgery. Patients undergoing cardiac operations registered in the Virginia Cardiac Services Quality Initiative and evaluated with the Society of Thoracic Surgeons predicted risk of mortality who required admission before surgery were included. Subsequently, patients were stratified by admission through the emergency department of the hospital where they were operated on or, when transferred from another hospital, were stratified by those hospitals with or without a cardiac surgery program.

The study included 13,094 patients; of these, 7582 were transfer patients, including 502 who were referred from cardiac centers. The transferred patients had increased hospital costs relative to those admitted through local emergency departments. They had equivalent postoperative morbidity, and in a risk-adjusted analysis, the transfer status was not independently associated with worse outcomes. Patients transferred from centers that performed cardiac surgery, however, were at higher risk than those transferred from hospitals without a cardiac surgery program (Society of Thoracic Surgeons predicted risk of mortality, $2.5 \%$ vs $1.5 \% ; P<.01)$. Excellent risk-adjusted outcomes after operations were observed, with an observed to expected ratio for mortality of 0.81 and an observed to expected ratio for combined morbidity or mortality of $0.90 ; 19 \%$ and $10 \%$ less than expected, respectively. Cost data were also obtained and revealed that transferred patients had a risk-adjusted increase in hospital cost of \$6141 and a 0.352-day increase in length of stay in the operating hospital.

Beller and colleagues ${ }^{1}$ concluded that "patients are being appropriately selected for transfer to centers best equipped to manage them." The other interesting aspect is that the sickest patients at highest risk were transferred from one cardiothoracic surgery center to another, probably related to the recognition by the cardiac surgeon at the referral site of additional risk variables not recorded in the Society of Thoracic Surgeons database, which led to the conclusion that the patient's risk was likely greater than the Society of Thoracic Surgeons calculated predicted risk of mortality score, thus leading to the referral of patients at higher risk. The excellent results rendered by the hospital to which they were referred, however, indicates an appropriate transfer of patients to where they could be best treated, usually an institution with higher specialization.

There has been much talk during the past several years about surgeons referring high-risk patients to another hospital because of the motivation of "risk avoidance." We believe that the vast majority of surgeons act in the best interest of their patients and therefore refer these high-risk patients to a tertiary center that they believe can achieve a better result than can be achieved in their own center. This behavior is laudable and represents a patientcentered viewpoint that reflects positively on our profession and specialty. We are all in this together, and together we need to focus on what is best for our patients. We believe that this well-written $\operatorname{article}^{1}$ supports this 
optimistic viewpoint, and it is a welcome addition to the Journal and to our specialty's literature. Remember, we are all in this together to deliver the best care possible for our patients.

\section{Reference}

1. Beller JP, Hawkins RB, Mehaffey JH, Chancellor WZ, Fonner CE, Speir AM, et al Impact of transfer status on real-world outcomes in nonelective cardiac surgery. J Thorac Cardiovasc Surg. 2020;159:540-50. 